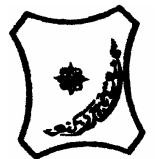

Bayero Journal of Pure and Applied Sciences, 5(2): $93-96$

Received: October 2012

Accepted: November 2012

ISSN $2006-6996$

\title{
EFFECT OF ANTIRETROVIRAL THERAPY ON SOME LIVER ENZYMES IN HIV/AIDS BREAST FED AND NON BREAST FED CHILDREN
}

\author{
${ }^{1}$ Kabir, N., ${ }^{2}$ Kiru, A.I., ${ }^{3}$ Kabir, H. And ${ }^{4}$ Yunusa, I. \\ ${ }^{1}$ Department of Chemical Pathology, Aminu Kano Teaching Hospital, Kano State, Nigeria. \\ ${ }^{2}$ Department of Biochemistry, Bayero University, Kano. \\ ${ }^{3}$ Department of Paediatrics, Aminu Kano Teaching Hospital, Kano State, Nigeria. \\ ${ }^{4}$ Department of Biochemistry, Kano University of Science and Technology, Wudil
}

Correspondence author: isayunusa@yahoo.com

\begin{abstract}
The relationship and effect of antiretroviral therapy with associated hepatotoxicity were investigated in different paediatric age groups using serum alanine and aspartate transaminases (ALT and AST) and alkaline phosphates (ALP) biomarkers. The study consisted of a total of one hundred and twenty (120) participants; fifteen (15) each from different age groups of HIV infected children at baseline and three (3) months after initiation of therapy as well as a control group. Ninety three percent (93\%) of the children studied acquired HIV infection through vertical transmission with seventy percent (70\%) having mixed feeding as their feeding pattern. Before

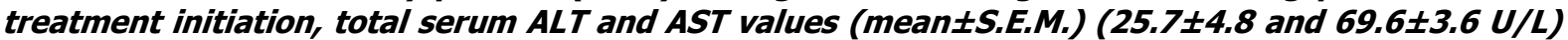
were significantly higher $(p<0.05)$ among the baseline than the control groups $(21.1 \pm 1.9$ and 17.9 $3.6 \mathrm{U} / \mathrm{L}$ ). After treatment, total serum transaminases and ALP values were found to be significantly lower $(p<0.05)$ among the treated $(24.4 \pm 3.6,38.4 \pm 5.4$ and $255.5 \pm 77.5 U / L)$ than the baseline (25.7 $\pm 4.8,69.6 \pm 3.6$ and $262.1 \pm 114.8 \mathrm{U} / \mathrm{L})$ groups, except for the children in the least age group. This study concluded that antiretroviral drugs have effect on liver enzymes and are risk factors for developing hepatotoxicity especially in children at lower age groups. Children therefore require frequent evaluation during antiretroviral therapy even in the absence of signs and symptoms of metabolic complications.
\end{abstract}

Keywords: Antiretroviral therapy, hepatotoxicity, transaminases, paediatric.

\section{INTRODUCTION}

During the past years, there seem to be an increase in the number of women with HIV in Kano State and the number of women with clinical AIDS (Federal Ministry of Health; FMOH, 2005). The high prevalence of HIV in women of reproductive age group and high fertility rates of African women are factors that contribute to the comparative high transmission of HIV infection to infants (FMOH, 2005). The primary route of infection in paediatric population is vertical transmission, accounting for virtually all new cases. Vertical transmission, i.e. mother-to-child transmission (MTCT) can occur (intrauterine) before, during (intrapartum), or after (through breast feeding) delivery (Behrman et al., 2004). Breastfeeding is the least common route of MTCT in industrialized nations (Behrman et al., 2004). However, this is an important transmission route in developing countries. Both free and cell associated virus have been detected in breast milk from HIVinfected mothers (Foster and Williamson, 2000).

A meta-analysis of prospective studies found that the additional risk of transmission through breast feeding in women with HIV infection before pregnancy was $14 \%$ compared with a $29 \%$ increase in breastfeeding women who acquire HIV postnatally. This suggests that the viraemia experienced by the mother during primary infection doubles the risk of transmission (WHO, 2005). Risk factors that influence the rate of vertical transmission include premature delivery, a low maternal antenatal $\mathrm{CD}_{4}$ count and the use of illicit drugs during pregnancy $(\mathrm{FMOH}, 2005)$. Unscreened blood or blood products, infected medical or surgical equipment and certain traditional medical practices put children at risk of being infected (UNAIDS, 2002). HIV infection in children as in adults is a chronic condition with wide spectrum of clinical expression, varying from no symptoms to AIDS (Bonhoeffers, 2003).

The advent of potent Antiretroviral drugs (ARVs) has enabled the transformation of HIV from a fatal to a chronic disease (WHO, 2005). Although not a cure, ARVs have dramatically reduced the mortality and morbidity and improve the quality of life of many (WHO, 2005). ARVs are classified as Nucleoside or (Nucleotide) Reverse Transcriptase Inhibitors (NRTIs), Non-Nucleoside or (Nucleotide) Reverse Transcriptase Inhibitors (NNRTIs) and Protease Inhibitors (PI). ARVs have been developed to target specific stages of the viral replication cycle (Behrman et al., 2004). However, the only regime potent enough is the High Active Antiretroviral Therapy (HAART) which involves combination of at least three ARVs (WHO, 2005). The use of all potent drugs is associated with adverse effects and ARVs are no exception (Kassaye and Katzestein, 2003). Virological and immunological surveillance as well as clinical and laboratory assessment and monitoring are recommended on all HIV/AIDS infected persons on ART (UNAIDS, 2002). 
UNAIDS (2002) recommended laboratory investigations as the basic level of care necessary in order to embark safety and informed decisions about switching between regimes. Therefore, this study is aimed at investigating the activities of some liver enzymes (AST, ALT and ALP) with a view to ascertain the adverse effects of ARVs in HIV/AIDS children from Murtala Muhammed Specialist Hospital, Kano, Nigeria.

\section{MATERIALS AND METHODS Study Site}

A prospective study was carried out at Murtala Muhammad Specialist Hospital, located strategically at the ancient city of Kano making the Hospital to be the most patronized in the State. Kano State occupies part of Northern Nigeria. The global location of the state is between latitude $11^{\circ} 30^{\prime}$ north of the equator and also between longitudes $08^{0} 30^{\circ}$ east of the Greenwich Meridian (Wikipedia, 2012).

\section{Study Subjects}

A total of one hundred and twenty (120) samples of HIV infected and non-infected children; fifteen (15) each in the different paediatric age distribution and fifteen (15) samples each from non-infected patients in each age (control) group participated in the study.

\section{Inclusion Criteria}

All children confirmed HIV positive whose caregivers gave informed consent following pre-test counseling, uninfected children confirmed non-infected, patients eligible for ART and symptomatic HIV/AIDS were included in the study.

\section{Exclusion Criteria}

Children whose caretakers did not give consent for the study and children on admission were not recruited for the study.

\section{Ethical Clearance}

Ethical clearance was sought from the ethical committee of Murtala Muhammad Specialist Hospital. All children were identified with the assistance of medical record clerks. Patients were enrolled into the study after informed consent had been secured following pre-test counseling. Socio-demographic and health status data were obtained using a structured questionnaire. Recommendations on when to initiate ART in children was based primarily on meta-analysis of data from 3941 children in Europe and United States of America using $\mathrm{CD}_{4}$ percentage and clinical symptom (WHO, 2005). Baseline assay and a follow up of three (3) months after initiation of ARVs were carried out. Control group comprised of uninfected children. Uninfected samples were from the voluntary counseling unit with informed consent of caregivers. Blood samples for control was obtained at the time when baseline sample were obtained from study group.

\section{Blood Sample Collection and Preparation}

Venous blood $(5 \mathrm{ml})$ each was obtained from study and control groups by veni-puncture. Blood was delivered into plain containers and allowed to clot. After clot retraction, blood was centrifuged at 3000rpm for 5 minutes. Later sera was harvested using clean and dry pasture pipettes into clean sample bottles, which were then capped, labeled and stored at $2-8{ }^{\circ} \mathrm{C}$ prior to analysis. Sera harvested were used for alanine and aspartate aminotransferases (ALT and AST) (Reitman and Frankel 1957) and alkaline phosphatase (ALP) (King and Armstrong, 1937) determinations respectively.

\section{Statistical Analysis}

Student's t test was used to compare mean values for ALT and AST, while analysis of variance (ANOVA) was used to compare between the three liver enzymes investigated.

\section{RESULTS AND DISCUSSION}

Table 1 shows that over ninety percent $(93.3 \%)$ of HIV infection in the children studied were due to mother-to-child transmission, $1.67 \%$ acquired the infection through blood transfusion while five percent $(5 \%)$ were undetermined cases of infection. This finding correlates with UNAIDS (2002) and Centre for Diseases Control; CDC (1999) which indicated that HIV trends by transmission group in children are primarily vertically acquired. Table 2 shows that almost twenty two percent $(21.7 \%)$ of the children were exclusively breastfed, seventy percent $(70 \%)$ mixed fed, while eight percent $(8.3 \%)$ were not breastfed. Department of Health and Human Services; DHHS (2000) also reported high risk of transmission from infected mothers to babies through breast milk. Therefore, avoidance of breastfeeding lowers the risk of HIV transmission from an infected mother (UNAIDS, 2002). On the other hand, non-breastfed infants may be prone to profound health risks, for example, not breastfeeding during the first two months of life is associated with six-fold increase in mortality due to infectious diseases (UNAIDS, 2002). Studies have indicated that mixed feeding is associated with higher risk of HIV infection and consequently increased metabolic complications caused by HIV virus (WHO, 2003).

Serum transaminases activities (Table 3) studied at baseline revealed that the ALT activity differs among the age groups and significantly higher $(p<0.05)$ than uninfected children. The AST activity was significantly higher $(p<0.05)$ in all the age groups, except for the uninfected children. 
This finding is in agreement with the study by Justice et al. (2002) who reported elevated liver transaminase enzymes activity in HIV infected patients not on drugs. This marked increased in AST may be as a result of viral induced trauma caused by HIV itself (a consequence of opportunistic pathogens).

The result of this study also revealed that three months after treatment initiation (Table 3), ALT activity in treated children was not significantly different $(p<0.05)$ from the baseline values, while the AST was found to be significantly higher when compared to the baseline values. This finding is similar to the findings of Montessori et al. (2003) but contrary to the study reported by Euglund et al. (1997) and Krogstad et al. (1999) which demonstrated an increase in both transaminase enzymes in children on ARV drugs. The most probable explanation for the rise in transaminases may be ascribed to differences in subjects' dietary intake, genetic variations, diseases and treatments factors as well as other baseline characteristics as indicated from questionnaire analysis. Observed mean difference in serum ALT of infected children after treatment initiation in the study age group 0 -11months old was found to be significantly higher $(P<0.05)$ compared to their baseline values (Table 3 ). This could be as a result of immaturity of some of the enzyme systems and probable less tolerability of the younger children to ARV drugs and are therefore at higher risk of developing hepatotoxicity.

Serum alkaline phosphatase activities studied (Table 4 ) at baseline were not significantly different ( $P$ $<0.05$ ) within the age groups but activities after treatment had significantly increased in all age groups, except for 10-12 years. This finding is similar to that reported by Azondekon et al. (2005) and Williams et al. (2003) which demonstrated an increase in bone loss during antiretroviral treatment resulting in consequent increase of osteoblastic activity which compensate for the bone loss.

Table 1: Mode of transmission of human immunodeficiency virus in HIV infected children

\begin{tabular}{lll}
\hline Mode of Transmission & Number & Percentage (\%) \\
\hline Mother-to-child & 56 & 93.33 \\
Transfusion recipients & 1 & 1.67 \\
Undetermined & 3 & 5.00 \\
Total & 60 & 100 \\
\hline
\end{tabular}

Table 2: Breastfeeding pattern in HIV infected children

\begin{tabular}{lll}
\hline Breastfeeding Pattern & Number & Percentage (\%) \\
\hline Exclusive & 13 & 21.70 \\
Mixed Feeding & 42 & 70.00 \\
Not Breastfed & 5 & 8.30 \\
Total & 60 & 100 \\
\hline
\end{tabular}

Table 3: Effect of antiretroviral treatment on ALT and AST enzymes in HIV infected children

\begin{tabular}{lllllll} 
& \multicolumn{2}{c}{ Baseline } & \multicolumn{2}{c}{ Treated } & \multicolumn{2}{c}{ Uninfected } \\
\hline Age group $(\mathbf{n})$ & ALT $(\mathbf{U} / \mathbf{L})$ & AST $(\mathbf{U} / \mathbf{L})$ & ALT (U/L) & AST (U/L) & ALT (U/L) & AST (U/L) \\
0-11 months & $23.1 \pm 4.2^{\mathrm{a}}$ & $83.1 \pm 2.5^{\mathrm{b}}$ & $29.9 \pm 2.7^{\mathrm{c}}$ & $41.6 \pm 7.1^{\mathrm{d}}$ & $15.9 \pm 1.1^{\text {aa }}$ & $14.9 \pm 1.5^{\mathrm{bb}}$ \\
$1-4$ years & $29.8 \pm 8.4^{\mathrm{a}}$ & $63.1 \pm 2.3^{\mathrm{b}}$ & $24.5 \pm 4.2 \mathrm{c}$ & $47.8 \pm 7.6^{\mathrm{d}}$ & $15.8 \pm 1.1^{\mathrm{aa}}$ & $15.3 \pm 1.3^{\mathrm{bb}}$ \\
$5-9$ years & $25.1 \pm 3.2^{\mathrm{a}}$ & $57.1 \pm 4.9^{\mathrm{b}}$ & $22.9 \pm 4.9 \mathrm{c}$ & $28.4 \pm 3.5^{\mathrm{d}}$ & $31.3 \pm 0.8^{\mathrm{aa}}$ & $21.6 \pm 7.9^{\mathrm{bb}}$ \\
$10-12$ years & $22.9 \pm 3.5^{\mathrm{a}}$ & $74.4 \pm 4.7^{\mathrm{b}}$ & $21.2 \pm 2.5 \mathrm{C}$ & $35.7 \pm 3.5^{\mathrm{d}}$ & $17.7 \pm 4.8^{\mathrm{aa}}$ & $17.9 \pm 3.5^{\mathrm{bb}}$ \\
\hline
\end{tabular}

Values are mean \pm S.E.M., $\mathrm{n}=15$ (number of subjects per each group). Values with similar superscripts in the same column are considered significant.

Table 4: Effect of antiretroviral treatment on ALP enzyme in HIV infected children

\begin{tabular}{llcl} 
& \multicolumn{3}{c}{ ALP $(\mathbf{U} / \mathbf{L})$} \\
\hline Age group $(\mathbf{n})$ & Baseline & Treated & Uninfected \\
$0-11$ months & $239.8 \pm 95.1^{\mathrm{a}}$ & $265.1 \pm 80.2^{\mathrm{f}}$ & $328.6 \pm 95.3^{\mathrm{k}}$ \\
$1-4$ years & $241.1 \pm 98.6^{\mathrm{b}}$ & $246.8 \pm 72.8^{\mathrm{g}}$ & $345.9 \pm 78.8^{\mathrm{I}}$ \\
$5-9$ years & $263.7 \pm 105.8^{\mathrm{c}}$ & $264.4 \pm 79.0^{\mathrm{h}}$ & $246.1 \pm 83.3^{\mathrm{m}}$ \\
$10-12$ years & $314.1 \pm 129.7^{\mathrm{d}}$ & $250.7 \pm 73.5^{\mathrm{I}}$ & $270.9 \pm 95.5^{\mathrm{n}}$ \\
\hline
\end{tabular}

Values are mean $\pm S . D, n=15$ (number of subjects per each group). Values with different superscripts in the same column are considered not significant.

\section{CONCLUSION AND RECOMMENDATION}

The results of this study indicate that antiretroviral drugs have effect on liver enzymes and are risk factors for developing hepatotoxicity especially in children at lower age groups. Children therefore require frequent evaluation during antiretroviral therapy even in the absence of signs and symptoms of metabolic complications. 


\section{REFERENCES}

Azondekon, A., Keitchion, A., Sangui, A., Atagnihoun, A., Atadokpede, F. and Azondekon, J. (2005): Side effects of antiretroviral therapy on children in Resource-limited Settings: Assessment and management. Journal of Acquired Immune Deficiency Syndrome. 153: $267-271$.

Behrman, R.E., Kliegman, R.M. and Jenson, H.B. (2004): Nelson Text Book of Paediatrics. $17^{\text {th }}$ ed. Thomson Press Ltd., India. Pp. 11091308.

Bonhoeffers, S. (2003): Glancing Behind virus Load Variation in Hrv-Irnfection. Trends in Microbiology. 11: 499-504.

Center for Diseases Control and Prevention (1994): Revised classification system for Human Immunodeficiency Virus infection in children less than 13 years of age. 43(12): 1-10.

Department of Health and Human Services (2000): guidelines for the use of antiretroviral agents in HIV infected adults and adolescents. HIV/AIDS Information Service (ATIS). 54: 25.

Euglund, J.A., Baker, C.J. and Raskino, C. (1997): Zidovudine, didnosine or both as the initial treatment for symptomatic HIV- infected children. AIDS Clinical Trials (ACTG) study152 team. Engld. J. Med. 336 (2): 1704-12.

Federal Ministry of Health (2005): Guidelines for the use of antiretroviral (ARV) drugs in Nigeria. National AIDS/STD Control Programme (NASCP). Pp. 1-42.

Foster, G. and Williamson, J. (2000): A review of current literature on the impact of HIV/AIDS in children in Sub-Saharan Africa. AIDS. 14: $275-84$

Justice, A.C., Wagner, J.H. and Fusco, G.P. (2002): HIV survival: Liver functions indefinitely predict survival, XIV. International AIDS Conference, Spain. 16:7-12.

Kassaye, S.G. and Katzenstein, D. (2003): HIV/AIDS care and treatment in Sub-Saharan Africa. Nature. 5 (4): 195-204.

King, E.J. and Armstrong, A.R. (1934): A Convenient Method for determining serum and bile phosphatase activity. Can-Med. Assoc. J. 31: $376-81$.

Krogstad, P. Wiznia, A. and Luzuriaga, K. (1999): Treatment of human immunodeficiency virus in infected infants and children with inhibtor nelfinavir mesylate. Clin Infect Dis. 28(5): $1169-18$.

Monntessori, V., Harris, M., and Montaner, J.S. (2003): Hepatotoxicity of nucleoside reverse transciptase inhibitor. Semin Liver Dis, 23(2): $183-94$.
Reittman, S. and Frankel, S. (1957): A colorimetric Method for the Determination of Glutamic Pyruvic Transaminase. Am. J. Clin. Path. 28: 56- 61.

UNAIDS (2002): Paediatric HIV infection and AIDS: UNAIDS point of view. UNAIDS. 3:1-1 0 .

WHO (2003): Scaling up antiretroviral therapy in Resourse-Limited Settings. Guidelines for a Public Health Approach. Pp. 89-92.

WHO (2005): HIV/AIDS antiretroviral newsletter: Antiretroviral therapy for children with HIV in Resourse-Limited Settings. Initiation and Changing Therapy. 11.

Wikipedia (2012): Kano State. In: http://en.wikipedia.org/wiki/Kano_State.

Williams, J.R., Hayward, R.M., Levin, M.J. and Sondheimer, J.M. (2003): Current paediatrics in diagnosis and treatment, $16^{\text {th }}$ ed. Lange Medical Book. Mc Graw Hill. Pp. 1140-1150. 